\title{
Molecular epidemiology of methicillin resistant Staphylococcus species in healthcare workers of a blood bank in the Brazilian Amazon
}

\author{
Cristina Motta Ferreira ${ }^{1 *}$, Roberto Alexandre Alves Barbosa Filho², Guilherme Motta Antunes Ferreira, ${ }^{1,3}$, \\ Marcus Vinicius Guimarães de Lacerda ${ }^{4,5}$, Cintia Mara Costa de Oliveira², Vanderson de Souza Sampaio 6,7, \\ Lucyane Mendes Silva ${ }^{1,3}$, Andreza Gomes Pascoal ${ }^{1}$ and William Antunes Ferreira ${ }^{8}$
}

\begin{abstract}
Background: Healthcare workers are susceptible to colonization by multiresistant bacteria, which can increase the risk of outbreaks.

Methods: Samples were collected from the nasopharynx, hands, and lab coats of healthcare workers. The phenotypic identification was carried out using a VITEK ${ }^{\circledR} 2$ rapid test system. PCR tests for the mecA gene and the sequencing of the amplicons were performed. Staphylococcus epidermidis and Staphylococcus aureus phylogenies were reconstructed using the Bayesian inference.

Results: A total of 225 healthcare workers participated in this study. Of these, $21.3 \%$ were male and $78.7 \%$ female. S. epidermidis and S.aureus showed high levels of resistance to penicillin, ampicillin, erythromycin, tetracycline and cefoxitin. The prevalence of methicillin resistant S. aureus was 3.16\% and methicillin resistant S. epidermidis was 100\%. Multilocus sequence typing identified 23 new S. epidermidis sequence types, and one new allele and sequence type for $S$. aureus. The frequency of methicillin-resistant S. epidermidis in nursing and hemotherapy technicians as a percentage of the total number of healthcare workers was $5.8-3.1 \%$, while the frequency of methicillin resistant $S$. aureus in hemotherapy technicians and biomedics, as a percentage of the total number of healthcare workers was 4.2-8.9\%\%.

Conclusions: The healthcare workers at the city's blood bank, even when taking the necessary care with their hands, body and clothes, harbour methicillin-resistant S. aureus and S. epidermidis sequence types, which, as a potential source of multidrug resistant bacteria, can contribute to nosocomial infections among hematological patients.
\end{abstract}

Keywords: S. epidermidis, Multirresistance, Oxacillin, ST, Clone

\section{Background}

Nosocomial infections continue to be a major clinical concern worldwide. In emerging countries, 1 in 100 hospitalized patients acquire such infections. Studies conducted in high-income countries identified that $5-15 \%$

\footnotetext{
*Correspondence: cris_motta_ferr@yahoo.com.br

${ }^{1}$ Fundação Hospitalar de Hematologia e Hemoterapia do Amazonas HEMOAM, Manaus, Brazil

Full list of author information is available at the end of the article
}

of the hospitalized patients acquire healthcare-associated infections, which can affect from 9 to $37 \%$ of those admitted to intensive care [1]. In the USA, the Center for Disease Control and Prevention-CDC calculated that annually there were approximately 1.7 million hospital infections from all types of microorganisms resulting in 99,000 deaths [2].

Nosocomial infections can damage not only the health of patients but also the health of staff. Hospitalized patients, especially those in the intensive care unit (ICU), 
[3-6] are particularly susceptible to nosocomial infections due to their immune systems being compromised by indwelling devices, underlying diseases, and prolonged overuse of broad-spectrum antibiotics [7].

When there is a lack of adherence to standard precautions, healthcare workers, especially nursing professionals (who were associated in the majority of the cases) are certainly more susceptible to colonization by multiresistant bacteria, and as a result may cause outbreaks $[6,8]$. However, the most common form of transmission, which favors the dissemination of these bacteria among patients and healthcare workers, is through contact that involves the hands $[6,9,10]$.

Staphylococci are the bacteria that are most frequently involved in hospital infections and colonize skin and nasal mucosa as their normal flora. Nasal carriage is one of the main sources for nosocomial infections among hospital staff $[9,11]$. When colonization occurs by multiresistant isolates, it becomes a risk factor for both the person who has been colonized and their contacts [10], and it is therefore of great clinical importance to identify which professionals are harbouring clones of dangerous, multi-resistant bacteria that are sources of nosocomial pathogenic clones [12]. Aproximately 30-94\% of healthcare workers carry methicillin-resistant Staphylococcus epidermidis (MRSE) and 16.8-56.1\% carry methicillinresistant Staphylococcus aureus (MRSA) in their nasal mucosa $[9,13]$, indicating that they may serve as important reservoirs and potential spreaders of these bacteria to uncolonized susceptible patients as well as being a source of nosocomial infections [13-15]. In the city of Manaus, Amazonas state, Brazil, as yet, no data has been produced regarding prevalence and/or levels of antimicrobial resistance to Gram-positive bacteria sequence types (STs) that colonize healthcare professionals, hence the importance of this study. The only data is from a study performed by Ferreira et al. [16], which identified new multi-resistant clones of S. epidermidis ST365 that were isolated from immunosuppressed patients who had been admitted to the city's blood bank, where this study was realized. Therefore, the aim of this study is the detection of multi-resistant S.epidermidis and S. aureus, their prevalence and phylogenetic relationships, and the results of antimicrobial susceptibility tests of a new sequence typing (ST) that were performed on healthcare workers at the Hematology and Hemotherapy Foundation of the Amazonas - HEMOAM.

\section{Methods}

\section{Study population and collection of samples}

This study was conducted at the city's public hematology center in Manaus, which is responsible for the diagnosis and treatment of outpatients and inpatients with malignant and benign hematological diseases. The public hematology center is also responsible for the care and control of blood and blood derivatives that are made available for the residents of the city of Manaus.

The recruitment of the study subjects and sample collections were carried out during the subjects' routine activities at HEMOAM, in 2015. Among the 400 healthcare workers at HEMOAM, 230 who maintained clinical and non-clinical contact with the patients agreed to participate in the study and signed the informed consent form. However, five healthcare workers were excluded due to the infeasibility of the samples during the development of the methodologies; therefore, 225 out of 400 subjects effectively participated in the study.

Three samples were taken from the nasopharynx, hands and lab coat of the subjects using three different sterile swabs that were placed in Stuart transport media (Labor Import, Guangzhou, China), and then transported to the Clinical Bacteriology Laboratory at HEMOAM.

\section{Cultivation, identification and susceptibility testing}

The primary sowing was carried out with $5 \%$ sheep blood agar and mannitol salt agar (Himedia-Hexasystems, Mumbai, India), which was then incubated for $24 \mathrm{~h}$ at $35.4^{\circ} \mathrm{C}$. Single isolated colonies were selected and phenotypic identification of MRSA and MRSE was performed using a rapid test system (VITEK ${ }^{\circledR} 2$, bioMérieux, France).

An in vitro antibiotic susceptibility test was performed using the standardized Kirby-Bauer disc diffusion method on a Mueller-Hinton agar plate with Gram-positive multi-discs (Laborclin, Paraná, Brazil) containing penicillin $(10 \mu \mathrm{g})$, gentamicin $(10 \mu \mathrm{g})$, oxacillin $(30 \mu \mathrm{g})$, sulfamethoxazol-trimethropim $(25 \mu \mathrm{g})$, chloramphenicol $(30 \mu \mathrm{g})$, ciprofloxacin $(5 \mu \mathrm{g})$, clindamycin $(2 \mu \mathrm{g})$, erythromycin $(15 \mu \mathrm{g})$, rifampin $(5 \mu \mathrm{g})$ and tetracycline $(30 \mu \mathrm{g})$. The plates were incubated for $24 \mathrm{~h}$ at $35.4^{\circ} \mathrm{C}\left(95.7^{\circ} \mathrm{F}\right)$. Methicillin and vancomycin resistance was tested using Mueller-Hinton agar with E test (MIC) and streaks of oxacillin and vancomycin antibiotic at a concentration ranging from 0.016 to $256 \mu \mathrm{g} / \mathrm{mL}$. Diameters of the zone of inhibition were measured and MIC interpretation of the reference values for sensitivity, reduced sensitivity or resistance to antibiotics were set according to the Clinical \& Laboratory Standards Institute manual (CLSI, 2015) [17].

Staphylococcus aureus (S. aureus) ATCC 25923 was used for the susceptibility tests. Aliquots of the MRSA and MRSE isolates were stored at $-80^{\circ} \mathrm{C}$ in a cryotube with Brain Heart Infusion (BHI) broth (Himedia, Hexasystens-Mumbai, India) $+20 \%$ glycerol, for further molecular testing. 


\section{Molecular characterization}

Methicillin resistant S. aureus and S. epidermidis isolates were submitted to molecular analysis and genomic DNA extraction was performed using the PureLink genomic DNA mini Kit (Invitrogen, CA, USA), and polymerase chain reaction was used to amplify the $m e c \mathrm{~A}$ gene, according to Jonas et al. [18]. Seven multilocus sequence typing (MLST) target genes were amplified using PCR according to the methods published for $S$. epidermidis and $S$. aureus available on the mlst. net webpage. The amplicons were sequenced with a 3130 Genetic Analyser (ABI 3130, Applied Biosystems, USA). The sequences were analysed using the Geneious software version 10.0.10 (Biomatters, New Zealand). Alleles and STs (sequencing types) were determined using the $S$. epidermidis (https://pubmlst.org/sepid ermidis/) and S. aureus (http://saureus.beta.mlst.net/) MLST databases.

\section{Allelic diversity of ST}

For the phylogenetic analysis of S. aureus and S. epidermidis, two local databases were built from all sequences annotated for each gene of the MLSTs (available in https://pubmlst.org), totaling 28,194 isolates for S. aureus and 1731 for S. epidermidis.

The sequences of the MLST genes were clustered and aligned with the $S$. aureus and S. epidermidis sequences isolated in this study ( 9 and 43 samples respectively), totaling 28,203 MRSA and 1774 MRSE samples, using the MAFFT tool (available in https://mafft.cbrc.jp/align ment/server) to the alignment. After the alignment of the sequences of each MLST gene, the Tajima neutrality test was performed in order to check whether the alleles were evolving in a stochastic manner or undergoing some form of selection [19]. The Tajima statistical test was performed with 1000 replicates, using the DnaSP 6 program, from the Universitat de Barcelona, current beta version: 6.12.03 (February 26, 2019), available at http://www.ub. $\mathrm{edu} / \mathrm{dnasp} /$.

\section{Phylogenetic analysis}

We used Markovian Chain Sampling (considering $1 \times 10^{6}$ generations and the evolutionary evolutive model GTR) [20] from the Mr. Bayes software version 3.2.6 [21] to estimate the phylogenetic relationships between the samples from the alignment of the concatenated MLST gene sequences isolated in this study. The phylogenetic relationships of the genetic distances between the STs were estimated using the comparative eBURST V3 software, which employed the eBURST algorithm (http://www. phyloviz.net/goeburst).

\section{Results}

Of the 400 healthcare workers at HEMOAM, 225 (56.2\%) were included in the study, of which 48 (21.3\%) were male and 177 (78.7\%) female. The mean age was 44 years of age. Of the total, 114 healthcare workers had regular contact with hospitalized patients or attended patients at the HEMOAM outpatient clinic. The distribution of the healthcare workers by type of work performed is shown in Table 1. Nursing technicians $(P$-value $=0.001)$ and administrative workers $(P$-value $=0.037)$ were associated with MRSE carriage, while for MRSA, the greatest association was with administrators $(P$-value $=0.036$ ).

The most frequent staphylococci species isolated were S. epidermidis $(n=45) ; S$. aureus $(n=284)$, and other saprophytic isolates $(n=319)$ were classified as Staphylococcus spp. The prevalence of MRSA was 3.1\% (9/284), MRSE was 100\% (45/45), and MSSA was 96.8\% (275/284).

An antimicrobial susceptibility test (AST) for MRSE ( $n=45)$ showed that $97.7 \%(44 / 45)$ were resistant to penicillin, $37.8 \%(17 / 45)$ to tetracycline, $35.5 \%(16 / 45)$ to sulfazotrim, $62.3 \%(28 / 45)$ to erythromycin, and $100 \%$ to oxacillin and cefoxitin (MRSE) with a minimum inhibitory concentration value (MIC $\mathrm{E}$ test) ranging from $0.25 \mu \mathrm{g} / \mathrm{mL}$ to over $256 \mu \mathrm{g} / \mathrm{mL}$. No association was identified between MRSE and gender, age, or profession (Supplementary material - S1).

The AST for MRSA $(n=9)$ showed that $88 \%$ were resistant to ampicillin, $67 \%(6 / 9)$ to tetracycline, $44 \%$ (4/9) to erythromycin and $100 \%$ to penicillin, oxacillin and cefoxitin, with a MIC E test ranging from $24 \mu \mathrm{g} / \mathrm{mL}$ to over $256 \mu \mathrm{g} / \mathrm{mL}$. Resistance to vancomycin was not detected, and phenotypic resistance to methicillin was confirmed by the detection of the mecA gene.

Multilocus sequence typing performed on 45 isolates of the S. epidermidis detected 22 new STs: ST661-669, ST643-653, ST670, and ST671. The remaining STs $(n=23)$ that were identified were ST20 $(n=6)$, ST296, ST61, ST152, ST173 $(n=2)$, ST194, ST17 $(n=3)$, ST2, ST153, ST255, ST185, ST69, ST59 $(n=2)$ and ST642.

Multilocus sequence typing performed for $S$. aureus detected one new gene (allele pta 680) and a new ST 5800 (ID 34725). The remaining STs $(n=8)$ were ST5 $(n=3)$, ST15 $(n=2)$, ST30, ST1993 and ST4952 (GenBank accession numbers: MW115983-115989; 115,990-115,996; 115,997-116,003; 116,004-116,010; $116,011-116,017 ; \quad 116,018-116,024 ; \quad 116,025-116,031$; $116,032-116,038 ; 116,039-116,045)$.

The distribution of the ST in relation to the origin of the sample locations and professions is shown in Table 2. It was also observed that the MRSE clone carriage was particularly high among nursing technicians, hemotherapy technicians and lab technicians, and MRSA clones 
Table 1 Distribution of the healthcare workers by profession and presence of MRSA/MRSE

\begin{tabular}{|c|c|c|c|c|c|c|c|c|}
\hline \multirow[t]{2}{*}{ Profession } & \multirow[t]{2}{*}{$\mathbf{n}$} & \multirow[t]{2}{*}{$\%$} & \multicolumn{3}{|c|}{ MRSA } & \multicolumn{3}{|c|}{ MRSE } \\
\hline & & & $\mathrm{n}$ & $\%$ & $P$-value & $n$ & $\%$ & $P$-value \\
\hline Physician & 13 & 5.8 & 0 & 0 & 0.616 & $2^{\mathrm{a}}$ & 4.4 & 0.291 \\
\hline Biochemist & 16 & 6.3 & 0 & 0 & 0.549 & 1 & 2.2 & 0.184 \\
\hline Nurse & 15 & 6.8 & 1 & 11.1 & 0.429 & 2 & 4.4 & 0.481 \\
\hline Nursing technician & 21 & 9.3 & 0 & 0 & 0.451 & $12^{\mathrm{a}}$ & 26.8 & 0.001 \\
\hline Nursing assistant & 2 & 0.9 & 0 & 0 & 0.930 & 1 & 2.2 & 0.325 \\
\hline Lab technician & 24 & 10.8 & 1 & 11.1 & 0.601 & 4 & 8.9 & 0.571 \\
\hline Hemotherapy technician & 53 & 23.6 & $5^{\mathrm{a}}$ & 55.6 & 0.091 & a & 15.6 & 0.112 \\
\hline Administrative staff & 48 & 21.3 & 0 & 0 & 0.142 & 4 & 8.9 & 0.037 \\
\hline Social worker & 5 & 2.3 & 0 & 0 & 0.833 & $3^{\mathrm{a}}$ & 6.7 & 0.217 \\
\hline Biomedic & 5 & 2.3 & 1 & 11.1 & 0.167 & 1 & 2.2 & 0.628 \\
\hline Ambulance driver & 4 & 1.8 & 0 & 0 & 0.864 & 1 & 2.2 & 0.546 \\
\hline Psychologist & 3 & 1.4 & 0 & 0 & 0.897 & 1 & 2.2 & 0.446 \\
\hline Physiotherapist & 3 & 1.3 & 0 & 0 & 0.897 & 1 & 2.2 & 0.446 \\
\hline Cleaning staff & 3 & 1.3 & 0 & 0 & 0.897 & $3^{\mathrm{a}}$ & 6.7 & 0.082 \\
\hline Librarian & 2 & 0.9 & 0 & 0 & 0.930 & 0 & 2.2 & 0.675 \\
\hline Lawyer & 2 & 0.9 & 0 & 0 & 0.930 & 0 & 0 & 0.675 \\
\hline Pharmacist & 1 & 0.5 & 0 & 0 & 0.964 & 0 & 0 & 0.822 \\
\hline Dentist & 1 & 0.5 & 0 & 0 & 0.964 & 0 & 0 & 0.822 \\
\hline Biologist & 1 & 0.5 & 0 & 0 & 0.964 & 1 & 2.2 & 0.178 \\
\hline Chemist & 1 & 0.5 & 0 & 0 & 0.964 & 0 & 0 & 0.822 \\
\hline Administrator & 1 & 0.5 & 1 & 11.1 & 0.036 & 0 & 0 & 0.822 \\
\hline Statistician & 1 & 0.5 & 0 & 0 & 0.964 & 1 & 2.2 & 0.178 \\
\hline Total & 225 & 100 & 8 & 100 & - & 40 & - & - \\
\hline
\end{tabular}

${ }^{a}$ These participants had two positive samples

Table 2 MRSA and MRSE ST distribution in relation to the sample location

\begin{tabular}{|c|c|c|c|c|c|c|c|}
\hline \multirow[t]{3}{*}{ Profession } & \multirow[t]{3}{*}{ n } & \multicolumn{6}{|c|}{ Sample location/clones (ST) } \\
\hline & & \multicolumn{2}{|c|}{ Hands - ST type } & \multicolumn{2}{|c|}{ Nasopharynx - ST type } & \multicolumn{2}{|c|}{ Lab coat - ST type } \\
\hline & & MRSA & MRSE & MRSA & MRSE & MRSA & MRSE \\
\hline Physician & 2 & - & 59 & - & 17 & - & - \\
\hline Biochemist & 1 & - & - & - & $644^{*}$ & - & - \\
\hline Nurse & 2 & - & 642 & - & $663^{*}$ & ST4952 & - \\
\hline Nursing technician & 12 & - & $59,653^{*}$ & - & $20,173,645^{*}, 661^{*}, 662^{*}$ & - & $20,69,152,255,646^{*}$ \\
\hline Nursing assistant & 1 & - & - & - & 173 & - & - \\
\hline Hemotherapy technician & 6 & ST15 & $666^{*}$ & - & $17,194,668^{*}$ & $\begin{array}{l}\text { ST15, ST5800* } \\
\text { ST5 }(n=2) \bullet\end{array}$ & $17,665^{*}$ \\
\hline Administrative staff & 4 & ST30 & $651^{*}$ & - & $647^{*}, 664,20$ & - & - \\
\hline Social worker & 3 & - & - & - & $2,61,296$ & - & - \\
\hline Biomedic & 1 & ST1993 & $670^{*}$ & - & - & - & - \\
\hline Lab technician & 5 & - & - & - & $20,643^{*}, 648^{*}, 652^{*}, 185$ & ST5 & - \\
\hline Psychologist & 1 & - & - & - & $667^{*}$ & - & - \\
\hline Biologist & 1 & - & - & - & $671^{*}$ & - & - \\
\hline Cleaning staff & 3 & - & - & - & $669^{*}, 649^{*}$ & - & $650^{*}$ \\
\hline Ambulance driver & 1 & - & - & - & - & - & 153 \\
\hline Physiotherapist & 1 & - & - & - & 20 & - & \\
\hline Statistician & 1 & - & - & - & - & - & 20 \\
\hline
\end{tabular}


were high only among hemotherapy technicians. All the MRSA and MRSE samples harboured the mec $A$ gene.

\section{Phylogenetic analysis}

We observed that when comparing the sum of alleles and types of ST of each clonal complex from the 28,203 MRSA data bank sequences selected for this study, that the clonal complexes $(\mathrm{CC}) \mathrm{CC} 5$ and $\mathrm{CC} 8$ presented the highest number of ST and presented most of the alleles of each MLST gene, as shown in Fig. 1. On the other hand, CC93 presented the lowest values of ST and alleles. The data revealed a strong positive correlation between the amount of STs and alleles of each analysed gene $(\mathrm{R}=0.998241)$.

The Tajima neutrality test (Table 3), with significance $P<0.01$, indicated that all the MLST regions are undergoing selection that favors an increase in the frequency of the most common allele and a decrease in the frequency of rare alleles for both S. aureus and S. epidermidis.

The allelic profile of each ST and CC is shown in Figs. 2 and 3 , as well as the genetic proximity according to the phylogenetic tree. S. aureus STs were distributed in three clonal complexes: CC5 that included ST5, ST1993, ST4952 and ST5800; CC15 that included ST15 and CC30 that included only ST30. ST 742 (CC97) was used as an external group for the $S$. aureus phylogenetic analysis.
The phylogenetic tree (Fig. 2A) presents a topology that groups the sequences by $\mathrm{CC}$, and reveals the monophyletic groups for the CC tree identified from $S$. aureus. The analysis of the e-Burst reveals the relationship among the STs, with ST5 as the founder of the others (Fig. 2B).

All of the $S$. aureus isolates that belong to CC5 $(n=6)$ showed $50 \%$ resistance to tetracycline, $66.6 \%$ to erythromycin, $33.3 \%$ to aztreonam and $83.3 \%$ to linezolid. The CC15 $(n=2)$ isolates showed resistance to tetracycline and aztreonam. The CC30 $(n=1)$ isolate was resistant to tetracycline, and showed sensibility to erythromycin, aztreonam and linezolid. None of the CC5, CC15 and CC30 isolates were susceptible to oxacillin, cefoxitin, penicillin and ampicillin.

The phylogenetic tree of $S$. epidermidis analysis group (ST2 as the external group - Fig. 3A) revealed the genetic proximity among the samples of $S$. epidermidis analysed in this study. We also observed strong monophyletic clusters formed between STs 17, 173 and 642; between STs 59 and 647 and also between STs 270, 650 and 669, which presented phylogenetic distance from the other sequences.

The e-Burst analysis revealed the relationship between the STs, with ST153 as the founder of the other STs (Fig. 3B). This analysis also showed that the samples of S. epidermidis were distributed in 33 different sequence

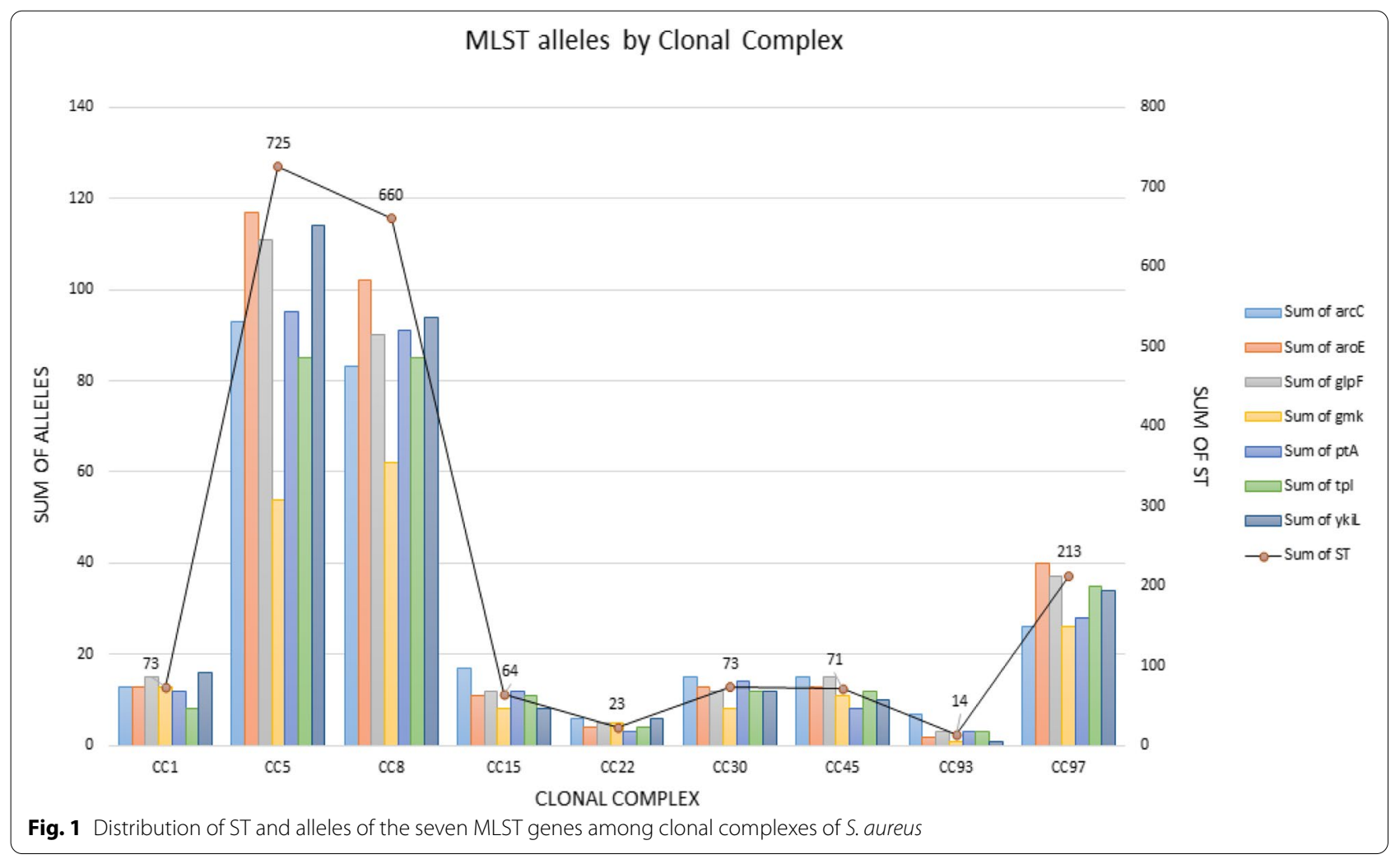


Table 3 Phylogenetic relationships between S. aureus clonal complexes, using the concatenated gene sequences from the MLST database

\begin{tabular}{|c|c|c|c|c|c|c|c|c|c|c|c|}
\hline \multirow[t]{2}{*}{ Microrganism } & \multirow[t]{2}{*}{ Gene } & \multicolumn{4}{|c|}{ Nucleotide composition (\%) } & \multirow[t]{2}{*}{ Lenght (n) } & \multirow{2}{*}{$\begin{array}{l}\text { Variable } \\
\text { sites (S) }\end{array}$} & \multirow[t]{2}{*}{$\mathrm{S} / \mathrm{n}(\mathrm{Ps})$} & \multirow[t]{2}{*}{$\Theta$} & \multirow[t]{2}{*}{$\pi$} & \multirow[t]{2}{*}{ Tajima's D } \\
\hline & & A & C & G & $\mathbf{T}$ & & & & & & \\
\hline \multirow[t]{7}{*}{ S. aureus } & $\operatorname{arcC}$ & 36.4 & 17.1 & 21.4 & 25.2 & 456 & 67 & 0.1469 & 0,0186 & 0.0068 & -1.6654 \\
\hline & aroE & 36.0 & 11.3 & 18.9 & 33.8 & 456 & 70 & 0.1535 & 0.0205 & 0.0099 & -1.3612 \\
\hline & glpF & 25.7 & 16.3 & 24.5 & 33.5 & 465 & 112 & 0.24 & 0.0318 & 0.0044 & -2.3522 \\
\hline & gmK & 37.2 & 12.4 & 21.2 & 29.3 & 417 & 53 & 0.127 & 0.0164 & 0.0083 & -1.2761 \\
\hline & ptA & 35.8 & 16.6 & 19.5 & 28.0 & 474 & 196 & 0.4135 & 0.0618 & 0.0068 & -2.4876 \\
\hline & tpl & 36.6 & 15.1 & 22.6 & 25.8 & 402 & 139 & 0.3458 & 0.0487 & 0.0096 & -2.2167 \\
\hline & yqiL & 34.0 & 15.6 & 22.4 & 28.0 & 516 & 68 & 0.1318 & 0.0162 & 0.0065 & -1.5817 \\
\hline \multirow[t]{7}{*}{ S. epidermidis } & $\operatorname{arcC}$ & 36.8 & 19.2 & 17.0 & 27.1 & 468 & 72 & 0.1538 & 0,0190 & 0.0153 & -0.5227 \\
\hline & aroE & 37.1 & 11.8 & 17.8 & 33.3 & 420 & 78 & 0.1857 & 0.0230 & 0.0110 & -1.3911 \\
\hline & gtr & 28.7 & 20.4 & 14.9 & 36.0 & 438 & 86 & 0.1963 & 0.0244 & 0.0119 & -1.3708 \\
\hline & muts & 30.4 & 19.8 & 11.4 & 38.4 & 412 & 48 & 0.1165 & 0.0144 & 0.0054 & -1.6011 \\
\hline & pyrR & 34.4 & 16.1 & 21.9 & 27.5 & 424 & 57 & 0.1344 & 0.0167 & 0.0086 & -1.2572 \\
\hline & tpiA & 34.6 & 16.0 & 22.0 & 27.4 & 424 & 67 & 0.1580 & 0.0196 & 0.0036 & -2.1526 \\
\hline & yqil & 31.6 & 15.2 & 21.5 & 31.6 & 416 & 62 & 0.1490 & 0.0185 & 0.0079 & -1.4948 \\
\hline
\end{tabular}

Nucleotide frequencies and parameters associated with the Tajima neutrality test for each MLST gene analysed. A, C, G and T are the percentages for each nucleotide in the genes in question. Size (n) corresponds to the total number of sites in each gene. Variable sites (S) correspond to the sites that showed nucleotide changes during alignments. Ps corresponds to the ratio $\mathrm{S} / \mathrm{n}$. $\Theta$ and $\pi$ correspond to values that measure nucleotide diversity. Tajima's $D$ corresponds to the reference parameter to verify the neutral theory of evolution for each gene. All values of Tajima's D showed statistical significance $P<0.01$

types. STs 17, 20, 59, 69 and 173 presented the highest frequencies, with $2,6,3,2$ and 2 samples respectively (3B).

All of the $45 \mathrm{~S}$. epidermidis STs showed resistance to oxacillin, cefoxitin; $97.7 \%$ of them were resistant to penicillin, $62.3 \%$ to erythromycin, $37.8 \%$ to tetracycline, and $35.5 \%$ to sulfazotrim. Resistance to vancomycin was not detected in any of the isolates.

\section{Discussion}

MRSA is recognized as an important pathogen related to healthcare-associated infections. In fact, S. epidermidis has distinguished itself as an important pathogen and the most prevalent that has been isolated from the hospital infection process. This is due to the use of implanted devices, the increased number of immunocompromised patients [6, 22], and also because of the large proportion of nosocomial isolates with decreased susceptibility to glycopeptides or resistance to antibiotics [22, 23].

S. epidermidis tends to accumulate different antibioticresistance determinants, such as penicillin, clindamycin, macrolide, tetracycline, methicillin, mupirocin, and vancomycin [14]. Therefore, it is currently recognized as a reservoir that is capable of transferring resistant genes to $S$. aureus [24], which makes antibiotic therapy even more difficult, and often causes treatment failures [25, 26].

The staff at HEMOAM, as in other studies [6, 8], regardless of their work category, also harbour MRSE and MRSA isolates on their hands, lab coats, and in their nasopharynx. Regardless of genetic characteristics, the same clonal type of MRSA (ST5, ST15) was also detected at the same sample location (nasopharynx and lab coat). These findings are in agreement with other studies carried out in countries such as Sweden [27], Jordan, Egypt, Pakistan [28], Brazil [8] and China [29].

The presence of MRSE and MRSA on the hands facilitates the nasal colonization of these professionals, due to the common habit of introducing the fingers in the nose $[11,15,28]$. Contamination of the hands usually occurs at the workplace itself, during the execution of laboratorial procedures, direct contact with the patients as well as the environmental surfaces surrounding the hospitalized patients, through gloves, computer keyboards and telephones [11]. Due to this constant exposure, they are easily colonized on the skin or in the nose, which makes them important transmission vectors and sources of hospital outbreaks $[10,29]$, and this constant exposure puts them and their families at risk $[8,10]$.

Another transmission vector of MRSA and/or MRSE is the lab coat, used by clinicians, nurses and technicians who work at the hospitals as well as healthcare workers at HEMOAM. According to Singh et al. [30], patient-topatient infections within hospitals and the community has been associated with the lodging of pathogens in lab coats of healthcare workers that also hang their coats in their cars, offices, or in improper environments outside the hospital areas such as in dining rooms, coffee shops and even shopping malls [31]. The seriousness of this 


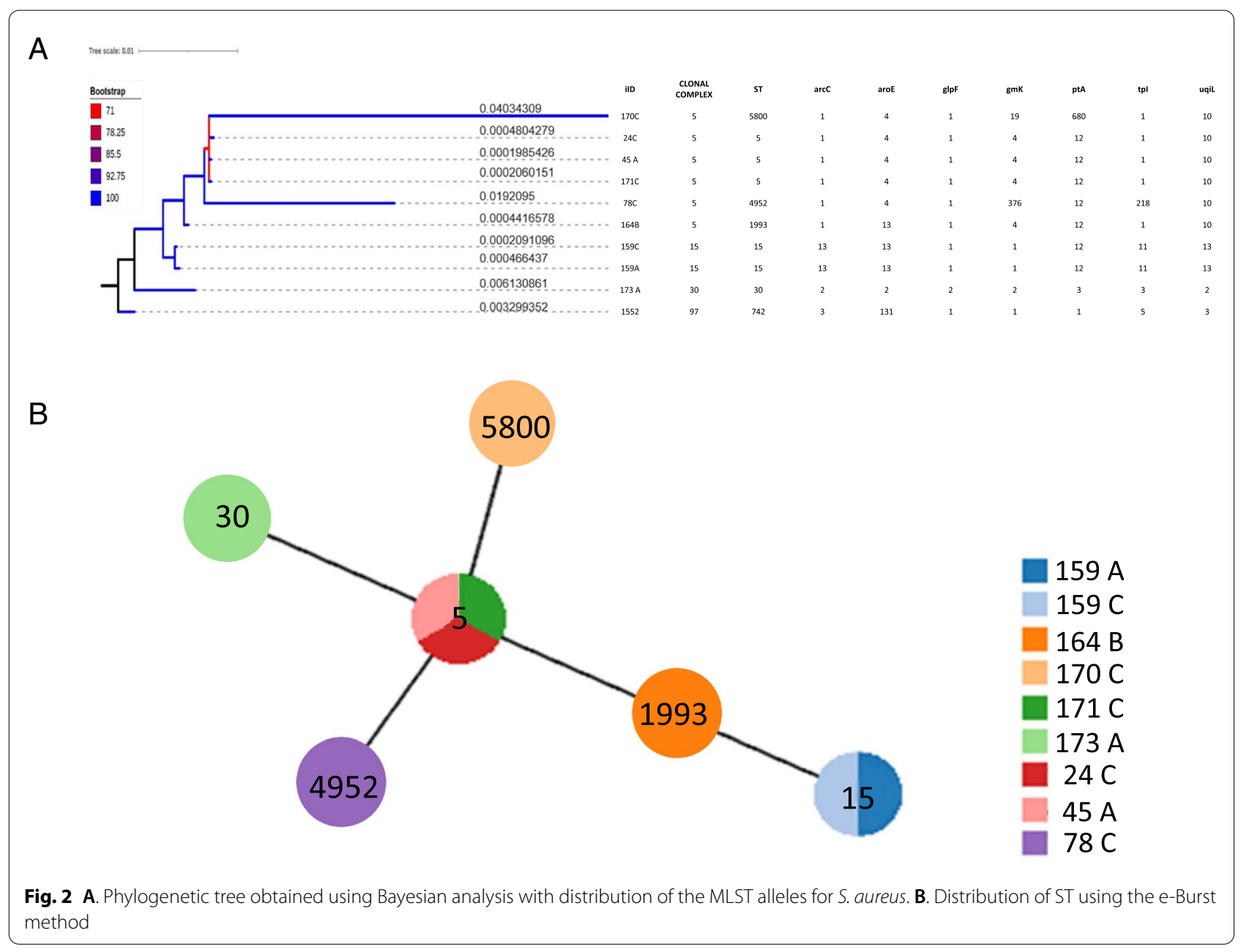

problem is related to the fact that the majority of these professionals are not concerned with the risk of contamination either due to arrogance or ignorance of the basic concepts of microbiology [31].

Different studies [31, 32] have also demonstrated that lab coats become progressively contamined during their use, and that the survival of the pathogens can last 10 to 100 days, thus confirming the environmental persistence and genetic adaptation of these pathogenic isolates, thus favouring the emergence of successful epidemic strains.

Since this study was carried out at a blood bank, where hematological patients are treated, and whose treatment may compromise the immune system, even if only temporarily, it is important to note that both the MRSA and MRSE harboured the mecA gene. These molecular aspects have been described previously in the studies developed by Lee et al., Grace et al. and Ehlers et al. [5, 31, 33].

In this study, the prevalence levels of MRSA and MRSE were 3.16 and $100 \%$, respectively. This is an important observation because, when compared with other studies, different results have been described. Among them, the studies carried out by Saffari et al.; Saadatian-Elahi et al.; Widerström et al.; Melendez et al.; Wang et al.; and Salman et al.; who identified levels of 70\% MRSE; $5.3 \%$ MRSA; 5.3\% MRSE, 85.5\% MRSE, 30\% MRSE and 9.3\% MRSA, respectively $[11,12,25,26,28,34]$. Certainly, this is a matter for concern, and one that requires strategic measures that can reduce the risks of transmission of these species in the blood bank.

In relation to MRSA, the high level of distribution occurred only among hemotherapy technicians (11.3\%). This frequency is similar to that described by other authors, such as Khatri S. et al., who found MRSA levels of $10.5 \%$ in lab technicians and $9.9 \%$ in nurses, while El-Aila et al. found $30.4 \%$ in nurses and $16 \%$ in doctors. However, Salman et al. identified MRSA levels of 25\% in laboratory staff and $10.8 \%$ in nurses, in Pakistan [28].

At the time of the collection of samples, the HEMOAM healthcare workers were harbouring different and 
A Tree scale: 0.001
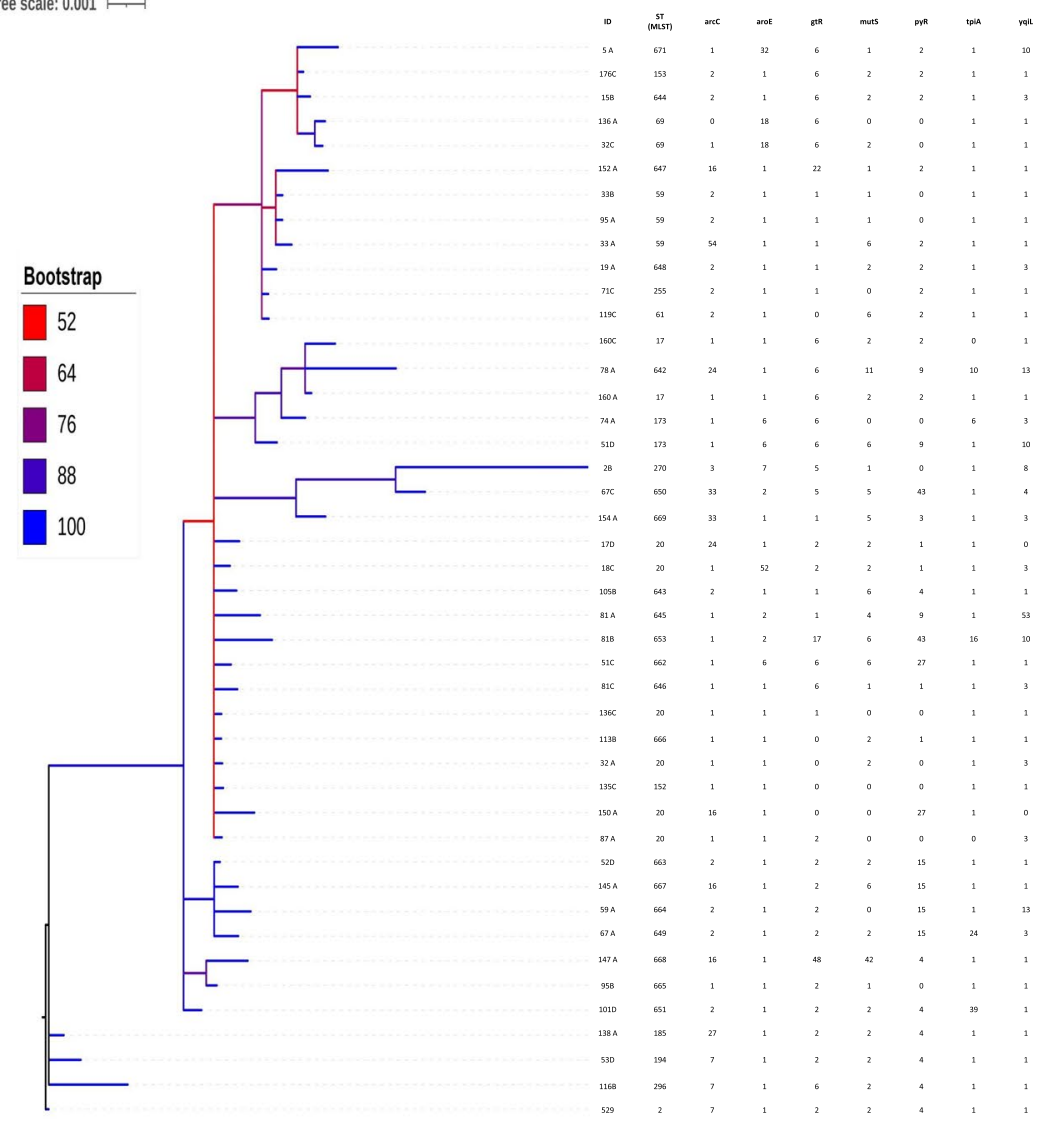

B

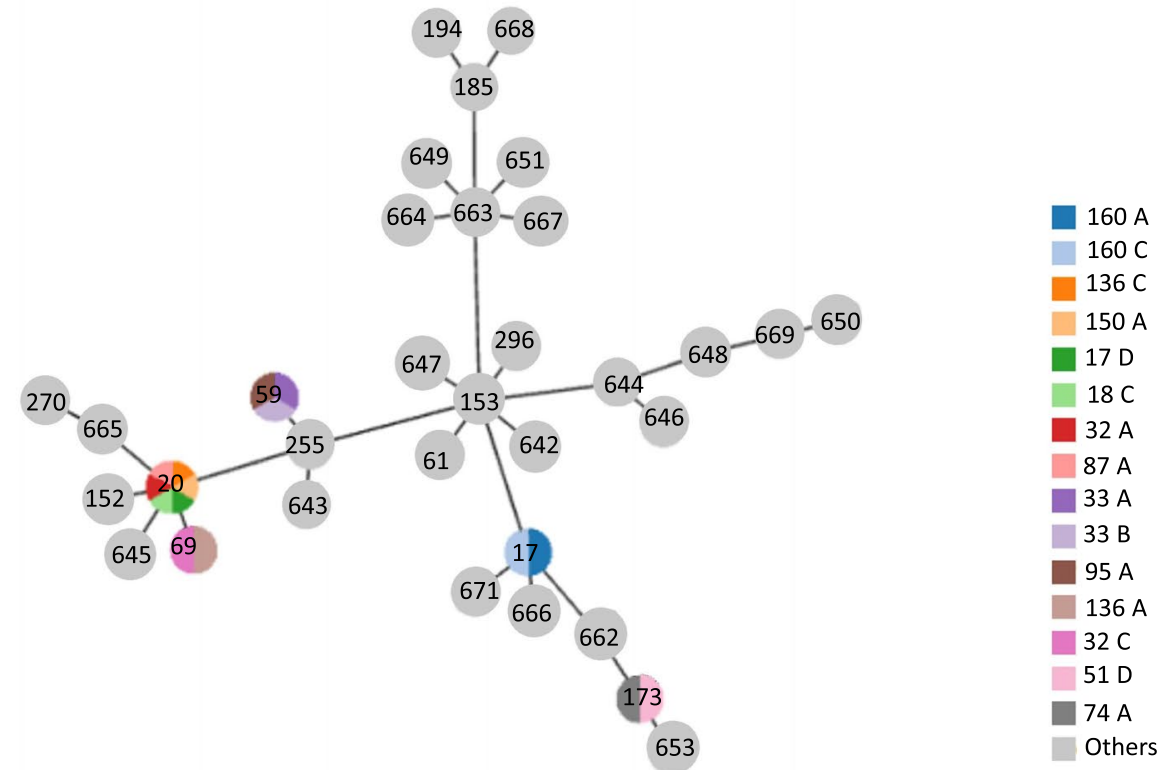

Fig. 3 A. Phylogenetic tree obtained by Bayesian analysis with distribution of the MLST alleles for S. epidermidis. B. Distribution of ST using the e-Burst method 
resistant STs that could probably be spread in the hospital. Furthermore, as they work in different hospital units, control measures to avoid transmission of these kinds of bacteria is extremely necessary, but control can be difficult $[35,36]$ and, if due care is not taken with prevention protocols, the transmission of these pathogens to high-risk patients will cause the emergence of hospital outbreaks.

In relation to MRSE, the susceptibility tests showed high percentages of resistance to different antibiotics such as penicillin, tetracycline, sulfamethoxazole-trimethoprim, and erythromycin. Ehlers et al., Xu et al., and Guo et al. also reported similar levels of resistance when testing clinical isolates of MRSE [29, 37, 38].

AST for MRSA isolates showed resistance to ampicillin, tetracycline, erythromycin, penicillin, oxacillin and cefoxitin. Salman et al. reported a resistance profile to azithromycin, ceftriaxone, oxacillin, cefoxitin, co-amoxiclav and ciprofloxacin, while Monteiro et al. reported resistance to oxacillin, clindamycin, erythromycin, ciprofloxacin and gentamicin [28, 39].

Regarding molecular analysis, this research identified 23 new STs of MRSE (ST) in healthcare workers. Despite the genetic evolution, different epidemic clonal lineages of MRSE have been identified in different hospitals throughout the world, most of them belonging to the clonal complex (CC) 2, which were mainly composed of ST2. This is possibly due to genetic evolutions and adaptations of these bacteria to the hospital environment, the antibiotic therapy, hospitalization of the patient, migrations and hygienic conditions [12, 39-41].

It was observed that ST59 is the most frequent ST clone that dominates the hospital environment and the major clone responsible for nosocomial infections that have already been reported in other studies conducted in Hungary, Spain, Mexico, Greece Sweden, Africa, China [26, 33, 40-42].

The new STs ST644, ST645, ST648, ST666, ST661, ST671 and ST670 came from the common ancestor ST153, which has also already been identified in five isolates of S. epidermidis in Ireland, and harbours ACME IV [43]. ST699 was reported in several countries such as India, Russia, Ireland, Denmark and the United States, and ST649, ST664, ST651, ST668 also have been described in countries like Germany, Switzerland, Poland, India, and Brazil, thus confirming the worldwide dissemination of these clones [http://www.mlst.net].

In this study, CC5 (ST5 $(n=3)$, ST1993, ST5800, ST4952 (6/9) 66.6\%) was the most common CC among MRSA isolates, with ST5 as the dominant clone. Gu et al. [29] in Shanghai also found 91.9\% of CC5 MRSA isolates among patients with MRSA blood stream infections, while, in a clinical samples at Galway University hospital,
Harrinson et al. [44] found ST5 isolates belonging to the CC5 MRSA.

In Spain, an analysis conducted by Montarelo et al. [45] over 15 years revealed that $\mathrm{CC} 5$ was also the most prevalent CC among MRSA isolates associated with methicillin resistance. In Latin American countries, with the exception of Ecuador, Brazil, and Colombia, CC5 MRSA was also prevalent in bloodstream infections [39, 40, 46, 47].

Recent studies have confirmed that multi-drug resistant and biofilm-producing pathogenic strains, which colonize inpatients or healthcare workers, caused different infectious processes in hospitals [38], and conventional antibiotics are not effective against biofilm, thus limiting therapeutic treatment [28]. Therefore, studies of the molecular epidemiology of pathogenic clones present in the hospital environment is of extreme importance, since the colonization of patients and healthcare workers may contribute to the emergence of nosocomial infections.

This study is important because, even with the measures taken to prevent hospital infection, it has shown the presence of pathogenic bacteria, such as MRSE and MRSA, in healthcare workers at HEMOAM, and the results will certainly contribute to improvements in the standard control measure protocols in order to avoid possible transmission to patients.

Currently, the hospital infection control committee $(\mathrm{CCIH})$ at HEMOAM monitors multi-resistant bacteria and the relevant preventive measures. Molecular protocols for the identification of multidrug-resistant pathogens are also being implemented to avoid infective treatment.

\section{Conclusion}

Our data desmonstrated the presence of pathogenic clones of MRSE and MRSA in healthcare workers at HEMOAM. It also showed that these professionals were a possible source of transmission and dissemination of these clones at the blood bank. Even with the control measures currently in use, the need for awareness and improvement of them is particularly important to prevent the colonization of these professionals and the likely transmittion to their families, colleagues and patients. This study also demonstrated the importance of identifying pathogenic clones of bacteria, their antimicrobial profile, and the use of the molecular technique, which can improve hospital care by preventing transmission and possible outbreaks.

\section{Abbreviations}

ABI 3130: Genetic Analyser 3130 Applied Biosystems; AST: Antimicrobial susceptibility test; ATCC: American Type Culture Collection; A, T, C, G: Adenine, cytosine, thymine and guanine.; $\mathrm{BHI}$ : Brain Heart Infusion; CC: Clonal 
complexes; CCIH: Hospital infection control committee; CDC: Center for Disease Control and Prevention; CLSI: Clinical and Laboratory Standards Institute; DNA: Deoxyribonucleic acid; eBURST: An algorithm that predicts the founding (ancestral) genotype.; GTR: General Time Reversible; HCAl: Health careassociated infections; HEMOAM: Hematology and Hemotherapy Foundation of the Amazonas; ICU: Intensive care unit; MAFFT: Multiple alignment software program for amino acid or nucleotide sequences; mecA: Part of staphylococcal chromosome cassette mec (SCCmec); MIC: Minimum inhibitory concentration; MLST: Multilocus sequence typing; MRSA: Methicillin-resistant S. aureuss; MRSE: Methicillin-resistant S. epidermidis; ST: Sequence Type; VITEK-2: Compact automated system for antimicrobial identification and susceptibility tests; USA: United States of America.

\section{Supplementary Information}

The online version contains supplementary material available at https://doi. org/10.1186/s12866-021-02365-1.

Additional file 1: Table S1. Multivariate logistic regression model for MRSE.

\section{Acknowledgements}

Not applicable.

\section{Code availability}

Not Applicable.

\section{Authors' contributions}

Data Curation: GMAF, LMS, AGP, CMF, WAF; Investigation and Methodology: LMS, GMAF, AGP, VSS, CMO, MVGL, CMF, WAF; Software formal analysis: RAABF, WAF, VSS; Visualization and Writing-Review \& Editing: WAF, CMF, RAABF, CMO, MVGL, VSS; Original draft preparation: WAF, RAAF, CMF; Conceptualization, Funding Acquisition, Project Administration, Resources: CMF, WAF. All authors read and approved the final manuscript.

\section{Funding}

The Amazonas State Research Foundation (FAPEAM) and Coordination for the Improvement of Higher Education Personnel (CAPES) research grants supported this work, including pos-graduated grants. The funders had no role in study design, data collection and anlysis, decision to publish, or preparation of the manuscript.

\section{Availability of data and materials}

The dataset(s) supporting the conclusions of this article is (are) included within the article (and its additional file(s)).

GenBank accession numbers: MW1 15983-115989; 115990-115996; $115997-$

116003; 116004-116010; 116011-116017; 116018-116024; 116025-116031;

116032-116038; 116039-116045. https://www.ncbi.nlm.nih.gov.

\section{Declarations}

\section{Ethics appoval and consent to participate}

This study was approved by the Human Research Ethics Committee at the Fundação Hospitalar de Hematologia e Hemoterapia do Amazonas HEMOAM, Manaus, Amazonas state, Brazil (CEP/HEMOAM), under (CAAE number 06033212.5.00000009).

The investigation conforms to the principles outlined in the Declaration of Helsinki. Health professionals enrolled in the study were informed about research aims and methods and provided their informed consent before specimens were collected, and the results and data were used for the management of each of the respective health professionals.

\section{Competing interests}

The authors report no conflicts of interest. The authors alone are responsible for the content and the writing of the paper.

\section{Author details}

${ }^{1}$ Fundação Hospitalar de Hematologia e Hemoterapia do Amazonas HEMOAM, Manaus, Brazil. ${ }^{2}$ Universidade Federal do Amazonas - UFAM, Manaus, Brazil. ${ }^{3}$ Programa de Pós-Graduação em Hematologia, Universidade do Estado do Amazonas - UEA, Manaus, Brazil. ${ }^{4}$ Fundação de Medicina Tropical Dr. Heitor Vieira Dourado - FMT-HVD, Manaus, Brazil. ${ }^{5}$ Instituto Leônidas e Maria Deane-Fiocruz, Manaus, Brazil. ${ }^{6}$ Universidade do Estado do Amazonas -

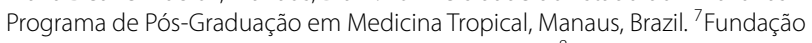
de Vigilância em Saúde do Amazonas, Manaus, Brazil. ${ }^{8}$ Fundação de Dermatologia Tropical e Venereologia Alfredo da Matta - FUAM, Manaus, Brazil.

Received: 22 April 2021 Accepted: 19 October 2021

Published online: 04 November 2021

\section{References}

1. Haque M, Sartelli M, Mckimm J, Bakar MA. Health care-associated infections - an overview. Infect Drug Resist. 2018;11:2321-33.

2. Elliott C, Justiz-vaillant A. Nosocomial Infections: A 360-degree Review. Int Biol Biomed J Spring. 2018;4(2):72-81.

3. Farzana K, Rashid Z, Akhtar N, Sattar A, Khan JA, Nasir B. Nasal carriage of staphylococci in health care workers: antimicrobial susceptibility profile. Pakistan J Pharmacol Sci. 2008;21(3):290-4.

4. Samuel SO, Kayode OO, Musa OI, Nwigwe GC, Aboderin A, Salami TA, et al. Nosocomial infections and the challenges of control in developing countries. Afr J Clin Exp Microbiol. 2010;11(2):102-10.

5. Grace J-U A, Olayinka BO, Onaolapo JA, Obaro SK. Staphylococcus aureus and coagulase-negative staphylococci in Bacteraemia: the epidemiology, predisposing factors, pathogenicity and antimicrobial resistance. Clin Microbiol Open Access. 2019;08(01):1-5.

6. de Costa DM, Kipnis A, de Leão-Vasconcelos LSNO, Rocha-Vilefort LO, Telles SA, André MCDPB, et al. Methicillin-resistant Staphylococcus sp. colonizing health care workers of a cancer hospital. Braz J Microbiol. 2014;45(3):799-805.

7. Quainoo S, Coolen JPM, van Hijum SAFT, Martijn A, Huynen WJGM, van Schaik W, et al. Whole-Genome Sequencing of Bacterial Pathogens : the Future of Nosocomial. Clin Microbiol Rev. 2017;30(4):1015-64.

8. Lopes LP, Pio DPM, Reinato LAF, Gaspar GG, Prado MA, Gir E. Staphylococcus Aureus in nursing professionals and the Microorganism'S susceptibility profile to antimicrobials. Texto Context Enferm. 2017;26(2):1-8.

9. Saadatian-Elahi M, Tristan A, Laurent F, Rasigade JP, Bouchiat C, Ranc AG, et al. Basic rules of hygiene protect health care and lab workers from nasal colonization by Staphylococcus aureus: An international crosssectional study. PLoS One. 2013;8(12).

10. E. Al-Abdli N, Baiu SH. Nasal Carriage of Staphylococcus in Health Care Workers in Benghazi Hospitals. Am J Microbiol Res [Internet] 2014;2(4):110-2. Available from: http://pubs.sciepub.com/ajmr/2/4/1/ index.html

11. Morgenstern M, Erichsen C, HackI S, Mily J, Militz M, Friederichs J, et al. Antibiotic resistance of commensal Staphylococcus aureus and coagulasenegative staphylococci in an international cohort of surgeons: A prospective pointprevalencestudy. PLoS One. 2016;11(2):1-16.

12. Agarwal $L$, Singh A, Agarwal A, Agarwal A. Methicillin and mupirocin resistance in nasal colonizers coagulase-negative Staphylococcus among health care workers. Med J Dr DY Patil Univ [Internet]. 2016;9(4):479. Available from: http://www.mjdrdypu.org/text.asp?2016/9/4/479/186070.

13. Rongpharpi SR, Hazarika NK, Kalita $H$. The prevalence of nasal carriage of Staphylococcus aureus among healthcare workers at a tertiary care hospital in Assam with special reference to MRSA. J Clin Diagn Res. 2013:7(2):257-60.

14. Widerström $M$, Wiström J, Edebro $H$, Marklund $E$, Backman $M$, Lindqvist $P$, et al. Colonization of patients, healthcare workers, and the environment with healthcare-associated Staphylococcus epidermidis genotypes in an intensive care unit: A prospective observational cohort study. BMC Infect Dis. 2016;16(1):1-8.

15. Legese H, Kahsay AG, Kahsay A, Araya T, Adhanom G, Muthupandian S, et al. Nasal carriage, risk factors and antimicrobial susceptibility pattern of methicillin resistant Staphylococcus aureus among healthcare workers in Adigrat and Wukro hospitals, Tigray, Northern Ethiopia. BMC Res Notes. 2018;11(1):1-6. 
16. Ferreira CM, Naveca FG, Ferreira WA, de Oliveira CMC, Barbosa M. Novel methicillin-resistant coagulase-negative Staphylococcus clone isolated from patients with haematological diseases at the blood bank Centre of Amazon, Brazil. Mem Inst Oswaldo Cruz. 2013;108(2):233-8.

17. Clinical and Laboratory Standards Institute. Performance Standards for Antimicrobial Susceptibility Testing; 25th Information Supplement M100-S25. Wayne: CLSI; 2015. p. 240.

18. Jonas D, Speck M, Daschner FD, Grundmann H. Rapid PCR-Based Identification of Methicillin-Resistant Staphylococcus aureus from Screening Swabs. J Clin Microbiol. 2002;40(5):1821-3.

19. Tajima F. Statistical methods to test for nucleotide mutation hypothesis by DNA polymorphism. Genetics. 1989;123:585-95.

20. Huelsenbeck JP, Ronquist F. MRBAYES: Bayesian inference of phylogenetic trees. Bioinformatics. 2001;17:754-5.

21. Tavaré S. Miura RM. Some probabilistic and statistical problems in the analysis of DNA sequences, Lectures on mathematics in the life sciences, 1986, vol. Volume 17 Providence (RI) American Mathematical Society (pg. 57-86)

22. Dortet L, Glaser P, Kassis-Chikhani N, Girlich D, Ichai P, Boudon M, et al. Long-lasting successful dissemination of resistance to oxazolidinones in MDR Staphylococcus epidermidis clinical isolates in a tertiary care hospital in France. J Antimicrob Chemother. 2018:41-51. Available from: http:// academic.oup.com/jac/article/doi/10.1093/jac/dk×370/4582307\%0A, http:// www.ncbi.nlm.nih.gov/pubmed/29092052.

23. Widerström M, Wiström J, Sjöstedt A, Monsen T. Coagulase-negative staphylococci: update on the molecular epidemiology and clinical presentation, with a focus on Staphylococcus epidermidis and Staphylococcus saprophyticus. Eur J Clin Microbiol Infect Dis. 2012;31(1):7-20.

24. de Benito S, Alou L, Becerro-de-Bengoa-Vallejo R, Losa-Iglesias ME, GómezLus ML, Collado L, et al. Prevalence of Staphylococcus spp. nasal colonization among doctors of podiatric medicine and associated risk factors in Spain. Antimicrob Resist Infect Control. 2018;7(1):1-7.

25. Saffari F, Widerström M, Gurram BK, Edebro H, Hojabri Z, Monsen T. Molecular and Phenotypic Characterization of Multidrug-Resistant Clones of Staphylococcus epidermidis in Iranian Hospitals: Clonal Relatedness to Healthcare-Associated Methicillin-Resistant Isolates in Northern Europe. Microb Drug Resist. 2016;22(7):570-577. Available from:http://online.liebe rtpub.com/doi/10.1089/mdr.2015.0283.

26. Martínez-Meléndez A, Morfín-Otero R, Villarreal-Treviño L, Camacho-Ortíz A, González-González G, Llaca-Díaz J, et al. Molecular epidemiology of coagulasenegative bloodstream isolates: detection of Staphylococcus epidermidis ST2, ST7 and linezolid-resistant ST23. Braz J Infect Dis. 2016;20(5):419-28.

27. Widerström M. Significance of Staphylococcus epidermidis in HealthcareAssociated Infections, from Contaminant to Clinically Relevant Pathogen-This Is a Wake-up Call! J Clin Microbiol. 2016;54(7):JCM.00743-16 Available from: http://jcm.asm.org/lookup/doi/10.1128/JCM.00743-16.

28. Salman MK, Ashraf MS, Iftikhar S, Baig MAR. Frequency of nasal carriage of staphylococcus aureus among health care workers at a tertiary care hospital. Pakistan J Med Sci. 2018;34(5):1181-4.

29. Gu F, He W, Xiao S, Wang S, Li X, Zeng Q, et al. Antimicrobial resistance and molecular epidemiology of Staphylococcus aureus causing bloodstream infections at Ruijin Hospital in Shanghai from 2013 to 2018. Sci Rep. 2020;10(1):1-8.

30. Singh G. Raksha. White coat of health care professionals as potential reservoir of microbial flora and MRSA. Indian J Basic Appl Med Res. 2019;8(2):505-15.

31. Zambon Dir L, Paulino WB, Trarbach LS, Martins JDL, Arpini CM. White coat as a contamination agent. J Pathogen Res. 2018;1(1):1-4.

32. Turner NA, Sharma-Kuinkel BK, Maskarinec SA, Eichenberger EM, Shah PP, Carugati M, et al. Methicillin- resistant Staphylococcus aureus: an overview of basic and clinical research. Nat Rev Microbiol. 2019;17:203-18.

33. Lee JYH, Monk IR, Gonçalves A, Seemann T, Chua KYL, Kearns A, et al. lineages of Staphylococcus epidermidis. Nat Microbiol. 2018;3:1-9. https://doi. org/10.1038/s41564-018-0230-7.
34. Ehlers MM, Strasheim W, Lowe M, Ueckermann V, Kock MM. Molecular epidemiology of Staphylococcus epidermidis implicated in catheterrelated bloodstream infections at an academic hospital in Pretoria, South Africa. Front Microbiol. 2018;9:1-11.

35. Wang Y, Lin J, Zhang T, He S, Li Y, Zhang W, et al. Environmental contamination prevalence, antimicrobial resistance andmolecular characteristics of methicillin-resistant staphylococcus aureus and staphylococcus epidermidis isolated from secondary schools in guangzhou, china. Int J Environ Res Public Health. 2020;17(2).

36. Okado JB, Bogni SC, Reinato LAF, Martinez R, Gir E, Camargo ILB da C. Molecular analysis of methicillin-resistant staphylococcus aureus dissemination among healthcare professionals and/or HIV patients from a tertiary hospital. Rev Soc Bras Med Trop. 2016;49(1):51-6.

37. Morgenstern M, Erichsen C, Hackl S, Mily J, Militz M, Friederichs J, et al. Antibiotic resistance of commensal Staphylococcus aureus and coagulasenegative staphylococci in an international cohort of surgeons: A prospective pointprevalence study. PLoS One. 2016;11(2):1-16.

38. Xu Z, Cave R, Chen L, Yangkyi T, Liu Y, Li K, et al. Antibiotic resistance and molecular characteristics of methicillin-resistant Staphylococcus epidermidis recovered from hospital personnel in China. J Glob Antimicrob Resist. 2020;22:195-201.

39. de Monteiro AS, Pinto BLS, de Monteiro JM, Ferreira RM, Ribeiro PCS, Bando SY, et al. Phylogenetic and molecular profile of Staphylococcus aureus isolated from bloodstream infections in Northeast Brazil. Microorganisms. 2019;7(7):1-14.

40. Mendes RE, Deshpande LM, Costello AJ, Farrell DJ. Molecular epidemiology of Staphylococcus epidermidis clinical isolates from U.S. hospitals. Antimicrob Agents Chemother. 2012;56(9):4656-61.

41. Guo Y, Ding Y, Liu L, Shen X, Hao Z, Duan J, et al. Antimicrobial susceptibility, virulence determinants profiles and molecular characteristics of Staphylococcus epidermidis isolates in Wenzhou, eastern China. BMC Microbiol. 2019;19(1):1-11.

42. Miragaia M, de Lencastre $H$, Perdreau-Remington F, Chambers HF, Higashi J, Sullam PM, et al. Genetic diversity of arginine catabolic mobile element in Staphylococcus epidermidis. PLoS One. 2009;4(11):1-9.

43. O'Connor AM, McManus BA, Coleman DC. First description of novel arginine catabolic mobile elements (ACMEs) types IV and V harboring a kdp operon in Staphylococcus epidermidis characterized by whole genome sequencing. Infect Genet Evol. 2018;(61):60-6.

44. Harrison EM, Ludden C, Brodrick HJ, Blane B, Brennan G, Morris D, et al. Transmission of methicillin-resistant Staphylococcus aureus in long-term care facilities and their related healthcare Networks. Genome Med. 2016;8(102):1-9.

45. Pérez-Montarelo D, Viedma E, Larrosa N, Gómez-González C, De Gopegui ER, Muñoz-Gallego I, et al. Molecular epidemiology of Staphylococcus aureus bacteremia: Association of molecular factors with the source of infection. Front Microbiol. 2018;9:1-11.

46. Arias CA, Reyes J, Carvajal LP, Rincon S, Diaz L, Panesso D, et al. A prospective cohort multicenter study of molecular epidemiology and phylogenomics of Staphylococcus aureus bacteremia in nine Latin American countries. Antimicrob Agents Chemother. 2017;61(10):1-12.

47. Rozas J, Ferrer-Mata A, Sánchez-DelBarrio JC, Guirao-Rico S, Librado P, Ramos-Onsins SE, et al. DnaSP 6: DNA sequence polymorphism analysis of large datasets. Mol Biol Evol. 2017;34:3299-302. https://doi.org/10. 1093/molbev/msx248.

\section{Publisher's Note}

Springer Nature remains neutral with regard to jurisdictional claims in published maps and institutional affiliations. 